\title{
Prenatal Detection of Congenital Heart Disease: Time for a Breakthrough
}

\author{
Karim A. Diab - Sawsan Awad
}

Published online: 19 December 2013

(c) Springer Science+Business Media New York 2013

To borrow Churchill's 1939 description of Russia, fetal wellbeing ever since man's creation was a "riddle, wrapped in a mystery, inside an enigma" till the advent of medical ultrasonography. We are now able to identify with increasing accuracy the intricacies of cardiac pathology; however, the rates of prenatal detection of congenital heart disease (CHD), the most common type of birth defects in humans, continue to be suboptimal at best. The reported rates have been quite disappointing, ranging between 15 and $48 \%$ with most being reported to be less than $30 \%$ [4, 6 , 9]. Even more recently, two published retrospective studies in high-risk populations at four major United States tertiary care centers, which take into account the use of more advanced technology and equipment, reported rates of detection of 24-36\% [5, 8]. This obviously continues to emphasize the poor prenatal detection rate and to stress the need for further improvement in this area.

This year, the American Institute of Ultrasound in Medicine (AIUM), in conjunction with the American College of Radiology (ACR), the American College of Obstetricians and Gynecologists (ACOG) and the Society of Radiologists in Ultrasound (SRU), published the revised practice guidelines for the performance of Obstetric Ultrasound Examinations [1]. These guidelines, like those previously published, include essential minimal or mandatory elements as part of the standard ultrasound examination of fetal anatomy during the second- and thirdtrimester scan. Unlike the previous guidelines, however, this year's publication includes a major change in screening the fetal heart in low risk pregnancies. The previous

K. A. Diab $(\bowtie) \cdot$ S. Awad

Pediatric Cardiology, Rush University Medical Center, 1653 W

Congress Parkway, Chicago, IL 606012, USA

e-mail: karim_diab@rush.edu guidelines state that a basic cardiac examination should include a 4-chamber view of the fetal heart and, only when "technically feasible", views of the outflow tracts. The current guidelines, finally, clearly emphasize the inclusion of both the right and left outflow tracts view in addition to the 4-chamber view as an integral part of the minimal elements of the ultrasonographic assessment of the fetal heart.

This significant change comes after various studies demonstrated the importance of adding the outflow tracts view to the routine prenatal screening ultrasound in addition to the four-chamber view. This has been shown to result in significant improvement in the detection rate of CHD of up to $70 \%$, as has been shown by Carvalho et al. [3] in a high-risk population and $74 \%$ as recently shown by a study by Levy et al. [7] in a large low-risk population. The outflow tracts view has been shown to be more sensitive than the four-chamber view in detecting $\mathrm{CHD}$ in general as well as in detecting ductal-dependent forms of CHD [8]. This leaves no doubt that, in order to achieve a better prenatal detection rate of CHD in the general population, the addition of the outflow views to the routine fetal screening examination has to become mandatory.

Given the importance of prenatal and early detection of congenital heart disease on postnatal outcome [2], these published practice guidelines will undoubtedly have a significant impact on the practice of fetal medicine. These guidelines represent an important effort to raise the bar and improve the rate of prenatal detection of CHD and as such advance the field of fetal cardiology.

The inclusion of the assessment of both the 4-chamber and outflow tracts views in the screening process in large low-risk pregnancies, however, undoubtedly places a significant burden on practicing obstetricians and obstetric sonographers, many of whom were not trained to obtain 
these views of the fetal heart. This imposes significant responsibility on the medical community, particularly on those who practice in the field of pediatric and fetal cardiology, to step up to the plate and help disseminate the practical implementation of these guidelines. This implementation needs to be widely disseminated similar to the initial guidelines which called for the inclusion of the fourchamber view in the routine scan. The idea of rotating obstetric sonographers with pediatric cardiologists has been suggested and followed in some institutions [7]. This was also the impetus for the development of combined obstetrical and fetal cardiology meetings to share theoretical as well as practical knowledge in this emerging field to thrust it beyond diagnosis and preparation for postnatal care to inutero therapy.

In the past decade several fetal cardiology conferences have been held, most received with much enthusiasm and solid attendance. We believe that these meetings will soon assume regularity and international recognition worthy of the impact progress in this field will provide.

\section{References}

1. American Institute of Ultrasound in Medicine (2013) AIUM practice guideline for the performance of Obstetric Ultrasound Examinations. J Ultrasound Med 32:1083-1101
2. Brown KL, Ridout DA, Hoskote A, Verhulst L, Ricci M, Bull C (2006) Delayed diagnosis of congenital heart disease worsens preoperative condition and outcome of surgery in neonates. Heart 92:1298-1302

3. Carvalho JS, Mavrides E, Shinebourne EA, Campbell S, Thilaganathan B (2002) Improving the effectiveness of routine prenatal screening for major congenital heart defects. Heart 88:387-391

4. Chew C, Halliday JL, Riley MM, Penny DJ (2007) Population based study of antenatal detection of congenital heart disease by ultrasound examination. Ultrasound Obstet Gynecol 29:619-624

5. Friedberg MK, Silverman NH, Moon-Grady AJ, Tong E, Nourse J, Sorenson B, Lee J, Hornberger LK (2009) Prenatal detection of congenital heart disease. J Pediatr 155:26-31

6. Garne E, Stoll C, Clementi M (2001) Evaluation of prenatal diagnosis of congenital heart diseases by ultrasound: experience from 20 European registries. Ultrasound Obstet Gynecol 17:386-391

7. Levy DJ, Pretorius DH, Rothman A, Gonzales M, Rao C, Nunes ME, Bendelstein J, Mehalek K, Thomas A, Nehlsen C, Ehr J, Burchette RJ, Sklansky MS (2013) Improved prenatal detection of congenital heart disease in an integrated health care system. Pediatr Cardiol 34:670-679

8. Sklansky MS, Berman DP, Pruetz JD, Chang RK (2009) Prenatal screening for major congenital heart disease: superiority of outflow tracts over the 4-chamber view. J Ultrasound Med 28:889-899

9. Tegnander E, Eik-Ness SH, Johansen OJ, Linker DT (1995) Prenatal detection of heart defects at the routine fetal examination at 18 weeks in a non-selected population. Ultrasound Obstet Gynecol 5:372-380 